\title{
Leptin is associated with disease activity but not with anthropometric indices in rheumatoid arthritis patients
}

Amela Dervišević ${ }^{1}$, Halima Resić ${ }^{2}$, Šekib Sokolovi $\hat{c}^{3}$, Nermina Babićc ${ }^{1}$, Nesina Avdagić ${ }^{1}$, Asija Začiragić ${ }^{1}$, Amela Bečiragić ${ }^{4}$, Almir Fajkić ${ }^{5}$, Orhan Lepara ${ }^{1}$, Almira Hadžović-Džuvo ${ }^{1}$

${ }^{1}$ Department of Human Physiology, Faculty of Medicine, University of Sarajevo,
Sarajevo, Bosnia and Herzegovina
${ }^{2}$ Clinic of Hemodialysis, University Clinical Center Sarajevo, Sarajevo, Bosnia and
Herzegovina
${ }^{3}$ Cardiology Clinic, University Clinical Center Sarajevo, Sarajevo, Bosnia and
Herzegovina
${ }^{4}$ Clinic of Hemodialysis, University Clinical Center Sarajevo, Sarajevo, Bosnia and
Herzegovina
${ }^{5}$ Department of Pathophysiology, Faculty of Medicine, University of Sarajevo, Sarajevo,
Bosnia and Herzegovina

Submitted: 17 June 2016

Accepted: 5 September 2016

Arch Med Sci 2018; 14, 5: 1080-1086

DOI: https://doi.org/10.5114/aoms.2017.65080

Copyright @ 2017 Termedia \& Banach

\section{Abstract}

Introduction: Leptin is a cytokine-like hormone which has a complex role in inflammation. However, the importance of leptin in the pathogenesis of rheumatoid arthritis (RA) is far from being fully elucidated. The aim of the study was to determine serum leptin levels in RA patients and to evaluate whether there is an association between disease activity, anthropometric indices and leptin levels.

Material and methods: This hypothesis-generating study included 55 RA patients and 25 matched healthy subjects. The serum leptin concentration was determined by enzyme-linked immunosorbent assay (ELISA).

Results: Median serum leptin level in RA patients of $27.4 \mathrm{ng} / \mathrm{ml}(14.5-54.9 \mathrm{ng} /$ $\mathrm{ml})$ was statistically significantly higher $(p=0.03)$ compared with the median leptin value of $16.3 \mathrm{ng} / \mathrm{ml}(9.6-38.8 \mathrm{ng} / \mathrm{ml})$ determined in healthy controls. The serum leptin level in the high disease activity group was significantly higher $(p<0.0005)$ than that in the low disease activity group and in healthy controls. A significant difference $(p=0.001)$ in serum leptin level was also found when the high disease activity group was compared with the moderate disease activity group. In the RA group a statistically significant positive correlation ( $r$ o $=0.390 ; p=0.003$ ) was observed between serum leptin level and disease activity score (DAS28).

Conclusions: The present results show that serum leptin levels are increased and significantly associated with disease activity in patients with RA and may have a valuable role in the inflammatory reactions and pathogenesis of RA.

Key words: rheumatoid arthritis, disease activity, leptin.

\section{Introduction}

Rheumatoid arthritis (RA) is a chronic, progressive, autoimmune disease characterized by synovial inflammation, cartilage damage and bone erosion [1]. The prevalence of RA in the general population is between $0.3 \%$ and $1 \%[2]$.

\author{
Corresponding author: \\ Amela Dervišević MD, MSc \\ Department \\ of Human Physiology \\ Faculty of Medicine \\ 90 Čekaluša St \\ 71000 Sarajevo \\ Bosnia and Herzegovina \\ Phone: +387 644368568 \\ Fax: +38733 203670 \\ E-mail: amela1610@yahoo. \\ com
}


It is a disease with a multifactorial etiology in which genetic predisposition and autoimmune factors as well as various environmental and life style risk factors (e.g. infections by microbial agents, smoking, obesity) contribute to disease susceptibility [3].

Although the pathogenesis of RA remains unknown, it is commonly believed that the overproduction of pro-inflammatory cytokines such as tumor necrosis factor- $\alpha$ (TNF- $\alpha$ ), interleukin-1 (IL-1), interleukin-6 (IL-6) and interleukin-17 (IL-17) plays a crucial role in the development of the disease [4].

The important role of adipokines, white adipose tissue (WAT) specific soluble proteins, in inflammation suggests that they may also contribute to the occurrence of RA [5].

Leptin is an obese (ob) gene product, a cytokine-like hormone synthesized predominantly by WAT, but also endothelial cells, T lymphocytes, bone marrow cells, spleen cells and platelets. Leptin belongs to the long-chain helical cytokine family and has structural similarity to IL-6, IL-12, IL-15, granulocyte colony-stimulating factor (G-CSF), oncostatin $M(O S M)$, prolactin and growth hormone. The leptin receptor, Ob-R, shows sequence homology to members of the class I cytokine receptor (gp130) family, which includes the receptor for IL-6, IL-12, OSM and prolactin [6]. Although the main role of leptin is to regulate body weight by inhibiting food intake and stimulating energy expenditure [7], recent evidence has indicated that leptin also influences reproduction, glucose homeostasis, hematopoiesis, angiogenesis, osteogenesis, wound healing and inflammation [8]. Furthermore, leptin takes part in the regulation of both innate and adaptive immune responses.

In innate immunity, leptin induces chemotaxis of neutrophils and the release of oxygen radicals through direct and indirect mechanisms [9]. Leptin also increases phagocytosis by monocytes/macrophages, and activates and promotes macrophage cell chemotaxis [10].

In adaptive immunity, leptin stimulates secretion, maturation, and survival of thymocytes, proliferation of naive T cells and differentiation to Th1 phenotype $[11,12]$. Leptin switches toward Th1 immune responses on memory $T$ cells by increasing interferon- $\gamma($ IFN- $\gamma$ ) and TNF- $\alpha$ secretion and by stimulating production of immunoglobulin $\mathrm{G} 2 \alpha$ (IgG2 $\alpha)$ by B cells [13].

In recent years, a variety of studies have been carried out, and their results suggest that leptin could be a member of the cytokine network managing the inflammatory immune response and host defense mechanisms [14]. Essentially, the interactions between leptin and inflammation are bidirectional: leptin regulates the production of pro-inflammatory cytokines such as TNF- $\alpha$, IL-1 and IL- 6 and, on the other hand, these cytokines increase the synthesis and release of leptin.

To our knowledge, the data regarding the relationship between serum leptin levels versus the activity or severity of the disease in patients with RA are still conflicting [15]. Certain publications describe serum leptin levels to be up-regulated in patients with RA [16], whereas others could not confirm this observation [15].

Bearing in mind the current disagreement over leptin involvement in RA, we generated the hypothesis that the inflammatory process and disease activity in RA are related to serum leptin levels.

\section{Material and methods}

\section{Study population}

This hypothesis-generating study included an initial sample of 63 RA patients and 31 randomly selected age- and gender-matched apparently healthy, medication-free, asymptomatic volunteers from the general population without clinical or biochemical signs and symptoms of RA or any other disease.

Rheumatoid arthritis patients diagnosed according to the 1987 American College of Rheumatology (ACR) revised classification criteria [17] were hospitalized in the Clinic for Heart, Blood Vessels and Rheumatism, University Clinical Center Sarajevo (UCCS), between January $1^{\text {st }}, 2011$ and June $30^{\text {th }}, 2011$.

The inclusion criteria included patients above the age of 18 years, either sex, fulfilling the ACR criteria for RA. The exclusion criteria were concomitant diseases including other rheumatic diseases, malignancy, active local or systemic inflammation caused by bacterial and viral infections, thyroid dysfunction, liver or kidney disease, current smokers, patients receiving statins, enzyme-inducing drugs or enzyme-inhibiting drugs.

This study population has been analyzed previously in a study where serum nitric oxide (NO) concentration was determined [18].

Eight RA patients were excluded from the initial sample: three because of diabetes mellitus, one because of hyperlipidemia and 4 patients refused to participate. A total of 55 RA patients fulfilled the inclusion criteria and were recruited to the study as the RA group for leptin determination. Twenty-five of 31 healthy individuals agreed to participate in a subsequent study as a control group for leptin determination.

Based on the stage of disease activity evaluated by the disease activity score (DAS28), patients with RA (RA group) were divided into three subgroups: low disease activity (DAS28 $\leq 3.2 ; n=14$ ), mod- 
erate disease activity $(3.2<$ DAS $28 \leq 5.1 ; n=19)$ and high disease activity (DAS28 $>5.1 ; n=22)$.

The study protocol was approved by the Ethical Committee of the UCCS, registered under number 0305-33957. All participants signed informed written consent after the explanation of the study procedure. All procedures were conducted in accordance with the guidelines of the World Medical Association Declaration of Helsinki for human subjects.

\section{Physical examination}

Detailed history was taken from patients using a specially prepared questionnaire that included questions relevant to RA such as disease duration, morning stiffness and drug taking history. At the time of blood sampling all the patients were receiving disease-modifying antirheumatic drugs (DMARDs). Methotrexate (MTX) was the most frequently prescribed DMARD, used by 51 patients (36 used MTX alone, 5 in combination with sulfasalazine, 3 in combination with cyclosporin, 7 in combination with TNF- $\alpha$ inhibitors) and the remaining 4 patients received sulfasalazine (2 used sulfasalazine alone, 2 in combination with cyclosporin). All patients underwent thorough clinical examination with special attention to articular examination.

The disease activity in RA patients was determined by an experienced physician with the use of DAS28. DAS28 is a mathematical formula with four variables: DAS28 $=0.56 \times \sqrt{ }($ TEN28 $)+0.28 \times$ $\sqrt{ }(\mathrm{SW} 28)+0.70 \times \operatorname{Ln}(\mathrm{ESR})+0.014 x(\mathrm{GH}) .($ TEN28: 28 joint count for tenderness, SW28: 28 joint count for swelling, Ln(ESR): the natural logarithm of Westergren's erythrocyte sedimentation rate (ESR); GH: general health or patient's global assessment of disease activity on the visual analog scale (VAS) of $100 \mathrm{~mm}$ ) [19].

\section{Anthropometric measurements}

Anthropometric measurements were obtained, including height, weight, waist and hip circumference. Height was measured to the nearest $0.5 \mathrm{~cm}$ using a stadiometer. Weight in light clothing and without shoes was measured to the nearest $0.1 \mathrm{~kg}$ on a digital scale. Waist circumference was measured at the approximate midpoint between the lower margin of the last palpable rib and the top of the iliac crest, using a stretch-resistant tape. The hip circumference was measured at the maximum circumference of the hip with the subjects in the standing position [20]. In the European Union waist circumference $\geq 94 \mathrm{~cm}$ in men and $\geq 80 \mathrm{~cm}$ in non-pregnant women are used as cut-offs for central obesity [21].

Body mass index (BMI) was calculated as weight $(\mathrm{kg})$ divided by height squared $\left(\mathrm{m}^{2}\right)$. Ac- cording to World Health Organization (WHO) criteria, BMI values in the range $18-25 \mathrm{~kg} / \mathrm{m}^{2}$ were considered as normal weight, $26-29 \mathrm{~kg} / \mathrm{m}^{2}$ as overweight, and BMI equal to or greater than $30 \mathrm{~kg} / \mathrm{m}^{2}$ as obese [22].

The waist-to-hip ratio (WHR) was determined by dividing the waist measurement by the hip measurement. The waist-to-height ratio (WHtR) was determined by dividing the waist measurement by the height measurement [23].

\section{Laboratory analysis}

Blood samples were collected by venipuncture between 8.00 and 10.00 a.m. in all patients and controls, following an overnight fast. Serum was separated by centrifugation and kept at $-80^{\circ} \mathrm{C}$ until estimation.

Leptin is exceptionally stable in frozen serum samples, over 2 years at $-20^{\circ} \mathrm{C}$ and over five freeze-thaw cycles [24]. Serum leptin concentration was determined by sandwich enzyme-linked immunosorbent assay (ELISA) technique, using a commercially available quantitative reagent kit (DRG Leptin EIA-2395, Germany) based on the sandwich principle with a limit of detection of $1.0 \mathrm{ng} / \mathrm{ml}$ at the Department of Immunology, UCCS, Sarajevo. Positive and negative controls were included in each test run.

\section{Statistical analysis}

The distribution of the variables was determined with the Shapiro-Wilk test and normality plots. An unpaired Student $t$-test or Mann-Whitney $U$-test was used to compare the difference between two groups, as appropriate. The correlations between the variables were assessed by Spearman's test. $P$-values less than 0.05 were considered statistically significant.

Data were analyzed using Statistical Package for the Social Sciences (SPSS) software version 13 (IBM, Chicago, Illinois, USA), and the results are presented as tables or figures. Values with normal distribution were expressed as mean \pm standard deviation, while those without normal distribution were shown as median and interquartile range.

\section{Results}

The baseline characteristics of RA patients and healthy controls are shown in Table I. The distribution of age, gender, BMI, waist circumference (WC), WHR, and WHtR were not statistically significantly different between the groups. The median disease duration in RA patients was 6 years (4.0-14.0 years).

Median serum leptin level of RA patients was $27.4 \mathrm{ng} / \mathrm{ml}(14.5-54.9 \mathrm{ng} / \mathrm{ml})$ and was statistical- 
ly significantly higher $(p=0.03)$ compared with median serum leptin level in healthy controls of $16.3 \mathrm{ng} / \mathrm{ml}(9.6-38.8 \mathrm{ng} / \mathrm{ml}$ ) (Figure 1).

Median serum leptin level in the group of patients with high disease activity of $58.65 \mathrm{ng} /$ $\mathrm{ml}(27.35-97.25 \mathrm{ng} / \mathrm{ml})$ was significantly higher $(p<0.0005)$ than that in the low disease activity group of $19.15 \mathrm{ng} / \mathrm{ml}(10.62-28.57 \mathrm{ng} / \mathrm{ml})$ and in healthy controls of $16.3 \mathrm{ng} / \mathrm{ml}(9.6-38.8 \mathrm{ng} / \mathrm{ml})$. A significant difference $(p=0.001)$ in serum leptin level was also found when the high disease activity group was compared with the moderate disease activity group (58.65 ng/ml (27.35-97.25 ng/ $\mathrm{ml})$ vs. $22.1 \mathrm{ng} / \mathrm{ml}(9.0-48.8 \mathrm{ng} / \mathrm{ml}))$. Comparing the serum leptin levels between other groups showed no significant difference (Figure 2).

A statistically significant positive correlation was observed between serum leptin level and BMI (rho $=0.697 ; p<0.0005), W C$ (rho = 0.590; $p=0.002$ ), and WHtR (rho $=0.510 ; p=0.009$ ) in the control group. No correlation was observed between serum leptin level and anthropometric indices (BMI (rho = 0.141; $p=0.306)$; WC (rho = $0.225 ; p=0.108) ; \mathrm{WHR}($ rho $=0.169 ; p=0.237$ ), WHtR (rho $=0.058 ; p=0.684)$ ) or disease duration (rho $=0.083 ; p=0.546)$ in the RA group (Table II).

A statistically significant positive correlation was observed between serum leptin levels and DAS28 score (rho $=0.390 ; p=0.003$ ) in the RA group (Figure 3).

\section{Discussion}

Although rheumatoid arthritis is a common autoimmune disorder, it is also associated with

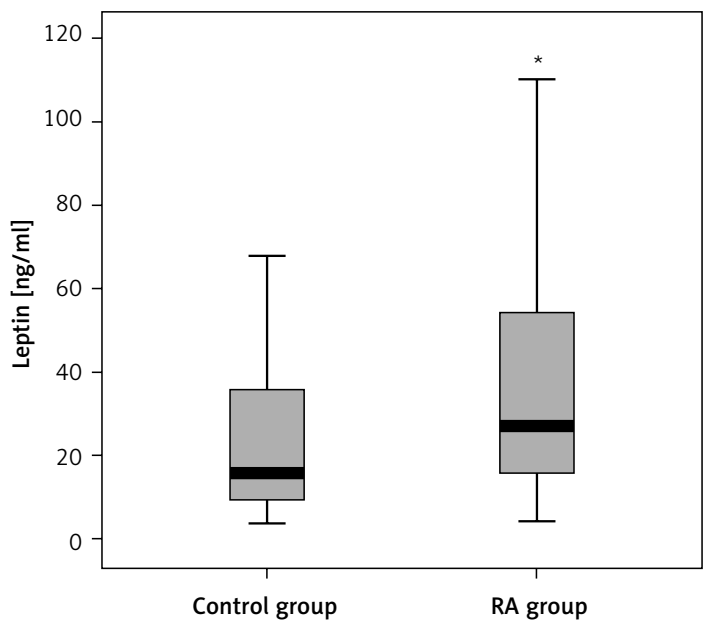

Figure 1. Box-and-whisker plots of serum leptin levels $(\mathrm{ng} / \mathrm{ml})$ in the RA group and healthy controls. The solid horizontal lines denote the median value, the box represents the $25 \%$ and $75 \%$ interquartile ranges, and the whiskers represent minimum and maximum values

${ }^{*} p=0.03$ compared with control group
Table I. Baseline characteristics of control group and RA group

\begin{tabular}{|lcc|}
\hline Variables & $\begin{array}{c}\text { Control group } \\
(n=25)\end{array}$ & $\begin{array}{c}\text { RA group } \\
(n=55)\end{array}$ \\
\hline Ages [years] & $50.6 \pm 7.4$ & $54.9 \pm 11.8^{\bullet}$ \\
\hline Sex (F/M) & $23 / 2$ & $51 / 4^{\bullet}$ \\
\hline $\begin{array}{l}\text { Disease } \\
\text { duration } \\
\text { [years] }\end{array}$ & $\mathrm{NA}$ & $6.0(4.0-14.0)$ \\
\hline BMI [kg/m²] & $27.0(22.9-30.2)$ & $26.0 \bullet(22.6-28.4)$ \\
\hline WC [cm] & $86.0 \pm 12.9$ & $91.3 \pm 12.1 \bullet$ \\
\hline WHR & $0.80(0.70-0.90)$ & $0.85^{\bullet}(0.79-0.91)$ \\
\hline WHtR & $0.50(0.45-0.60)$ & $0.53^{\bullet}(0.48-0.59)$ \\
\hline
\end{tabular}

Data are presented as mean $\pm S D$; median $\left(25^{\text {th }}\right.$ and $75^{\text {th }}$ percentiles); BMI - body mass index, WC - waist circumference, WHR - waist-to-hip-ratio, WHtR - waist-to-height ratio, RA group patients with rheumatoid arthritis, $n$ - number of cases, NA - not applicable, NS - not significant, $p$ - probability, $\cdot p=N S$ - compared with control group.

a chronic inflammatory response. Recently, it was shown that adipocytes surrounding the RA joints secrete adipokines that may regulate inflammatory and immune processes [25]. However, the mechanism of leptin performance, as a pleiotropic molecule, within arthritic inflammation remains unclear. Currently published data regarding the association between plasma/serum leptin levels and RA are contradictory.

The results of our study showed that the serum leptin level was significantly higher in RA patients

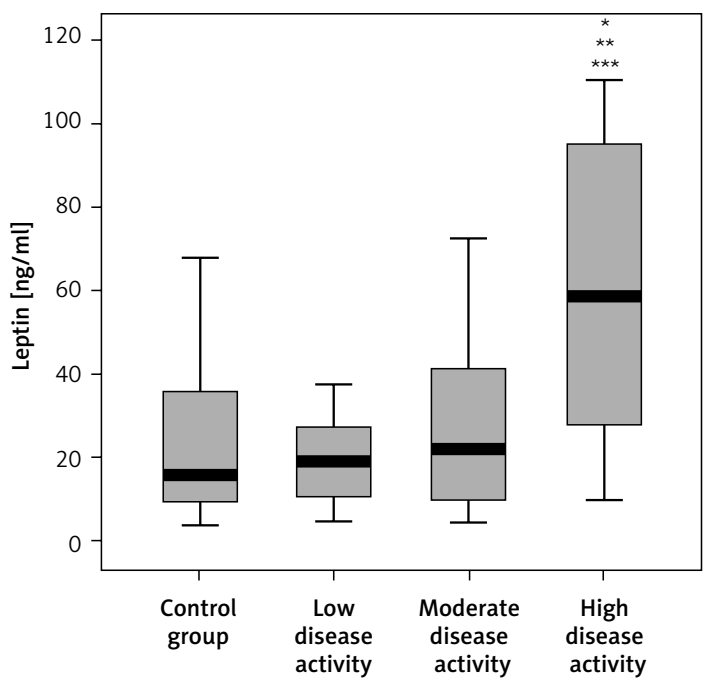

Figure 2. Box-and-whisker plots of serum leptin levels $(\mathrm{ng} / \mathrm{ml})$ in the RA patients with different disease activity and healthy controls. The solid horizontal lines denote the median value, the box represents the $25 \%$ and $75 \%$ interquartile ranges and the whiskers represent minimum and maximum values ${ }^{*} p<0.0005$ compared with control group, ${ }^{* *} p<0.0005$ compared with low disease activity, ${ }^{* * *} p=0.001$ compared with moderate disease activity. 
Table II. Correlations of serum leptin levels with disease duration and anthropometric indices in control group and RA group

\begin{tabular}{|lcccc|}
\hline \multirow{2}{*}{ Variables } & \multicolumn{3}{c|}{ Leptin $[\mathrm{ng} / \mathrm{ml}]$} \\
\cline { 2 - 5 } & \multicolumn{2}{c|}{ Control group $(n=25)$} & \multicolumn{2}{c|}{ RA group $(n=55)$} \\
\cline { 2 - 5 } & \multicolumn{1}{c}{ Rho } & P-value & 0.083 & $P$-value \\
\hline Disease duration [years] & \multicolumn{2}{c}{ NA } & 0.141 & 0.546 \\
\hline BMI $\left[\mathrm{kg} / \mathrm{m}^{2}\right]$ & 0.697 & $<0.0005$ & 0.225 & 0.306 \\
\hline WC $[\mathrm{cm}]$ & 0.590 & 0.002 & 0.169 & 0.108 \\
\hline WHR & 0.200 & 0.337 & 0.058 & 0.237 \\
\hline WHtR & 0.510 & 0.009 & 0.684 \\
\hline
\end{tabular}

BMI - body mass index, WC - waist circumference, WHR - waist-to-hip-ratio, WHtR - waist-to-height ratio, RA group - patients with rheumatoid arthritis, $n$-number of cases, NA - not applicable, rho-Spearman correlation coefficient, $p$ - probability.

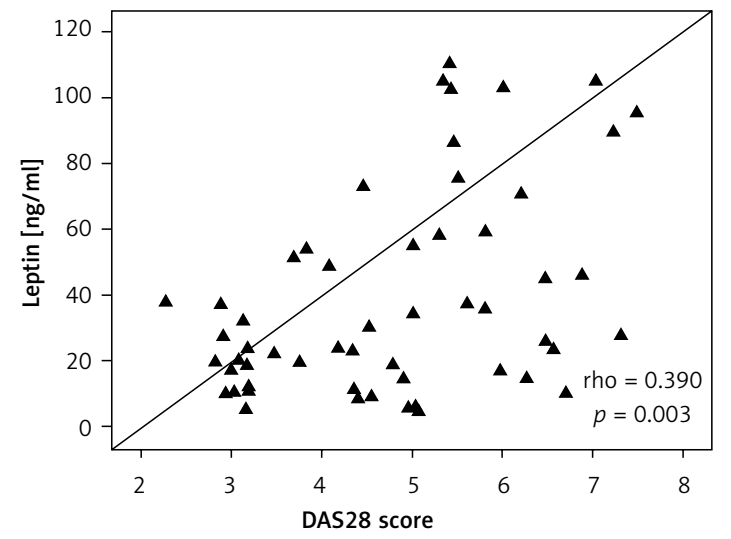

Figure 3. Correlation between serum leptin levels and DAS28 score in RA group

compared with the healthy controls. The obtained results are consistent with the results of Seven et al. [26], who found significantly higher serum and synovial fluid leptin levels in RA patients than in the control group. Our study also confirmed results reported by Sarraf et al. [27], who reported that in the process of chronic inflammatory diseases, pro-inflammatory cytokines (IL-1 and TNF- $\alpha$ ) increase obese gene expression and leptin secretion.

According to the results of Rho et al. [28], the higher concentrations of leptin in patients with RA than controls can be attributed to differences in inflammation rather than BMI.

Leptin has pro-destructive and pro-inflammatory effects on cartilage. Human chondrocytes express the leptin receptor $\mathrm{Ob}-\mathrm{Rb}$ and, when acting together with IFN- $\gamma$, leptin stimulates NO production in the joint cavity. NO contributes to the destruction of cartilage by inhibiting the synthesis of collagen and proteoglycans and enhancing apoptosis of chondrocytes [29]. However, in our previous study we did not find a statistically significant difference between serum NO values in RA patients and healthy controls [18].
In the present study, there was no correlation between serum leptin levels and anthropometric measurements (BMI, WC, WHR and WHtR) in the group of patients with RA, but positive correlations between serum leptin levels and BMI, WC and WHtR were found in healthy individuals.

Our results are in agreement with the findings of Seven et al. [26], who also reported no correlation between plasma leptin concentration and BMI in RA patients and suggested that regulation of leptinemia is very complex and that weight is not the only major regulator of leptin concentration. On the other hand, a positive correlation between serum leptin concentration and BMI in patients with RA was found in a study by Allam et al. [30].

Leptin was not found to be significantly correlated with disease duration in the current study. This is in agreement with the findings of Popa et al. [31], who also found that serum leptin levels in RA patients were not related to disease duration.

Although the majority of studies determined high serum leptin levels in patients with RA, some other studies did not support these results. In contrast to our results, Hizmetli et al. [32] reported no differences between serum levels of this adipokine in RA and healthy subjects. Targojska-Stdpniak et al. [33] also found that mean serum leptin concentration in their RA patients remained within the normal range. Tokarczyk-Knapik et al. [34] reported lower mean serum leptin concentration in patients with RA than in the control group. These authors suggested that the physiologic relation of serum leptin to body fat stores is not present in patients with RA.

In our study, patients with high disease activity showed statistically significantly higher serum leptin levels then healthy controls and patients with low and moderate disease activity.

This is in agreement with the findings of Lee et al. [35], who also reported significantly higher serum leptin levels in RA patients with high dis- 
ease activity, as well as positive correlations between leptin and DAS28 score. Similarly, Seven et al. [26] reported that RA patients with moderate disease activity had significantly higher leptin levels than those with low disease activity.

In the present study, a significant positive correlation was found between serum leptin levels and DAS28 score. The obtained results suggest that adipose tissue leptin secreting activity is increased in patients as the disease progresses, which may be associated with the pro-inflammatory role of leptin in RA.

Further, longitudinal prospective studies involving a larger population are needed to confirm the findings of the present study and to better understand the role of leptin in the pathogenesis of rheumatoid arthritis.

In conclusion, we observed that serum level of leptin in patients with RA was significantly higher than that in the control group. Serum level of leptin in the RA patients was correlated with disease activity but not with BMI or disease duration. Our findings indicate that leptin itself has an important role in the inflammatory process in RA patients and may be a valuable marker in monitoring disease activity.

\section{Conflict of interest}

The authors declare no conflict of interest.

\section{References}

1. Scott DL, Wolfe F, Huizinga TW. Rheumatoid arthritis. Lancet 2010; 376: 1094-108.

2. Noviello Mde L, Batista NV, Dourado LP, et al. Prolonged ingestion of ovalbumin diet by Ova sensitized mice suppresses mBSA-induced arthritis. Cell Immunol 2013; 284: 20-8.

3. Magyari L, Varszegi D, Kovesdi E, el al. Interleukins and interleukin receptors in rheumatoid arthritis: research, diagnostics and clinical implications. World J Orthop 2014; 5: 516-36.

4. Smolen JS, Steiner G. Therapeutic strategies for rheumatoid arthritis. Nat Rev Drug Discov 2003; 2: 473-88.

5. Gómez R, Conde J, Scotece M, Gómez-Reino JJ, Lago F, Gualillo $\mathrm{O}$. What's new in our understanding of the role of adipokines in rheumatic diseases? Nature Rev Rheumatol 2011; 7: 528-36.

6. La Cava A, Matarese G. The weight of leptin in immunity. Immunology 2004; 4: 371-9.

7. Begenik H, Aslan M, Dulger AC, et al. Serum leptin levels in gastric cancer patients and the relationship with insulin resistance. Arch Med Sci 2015; 11: 346-52.

8. Boguszewski CL, Paz-Filho G, Velloso LA. Neuroendocrine body weight regulation: integration between fat tissue, gastrointestinal tract, and the brain. Endokrynol Pol 2011; 61: 194-206.

9. Caldefie-Chezet F, Poulin A, Vasson MP. Leptin regulates functional capacities of polymorphonuclear neutrophils. Free Radic 2003; 37: 809-14.

10. Fenton JI, Hursting SD, Perkins SN, Hord NG. Leptin induces an Apc genotype-associated colon epithelial cell chemokine production pattern associated with macrophage chemotaxis and activation. Carcinogenesis 2007; 28: 455-64.

11. Howard JK, Lord GM, Matarese G, et al. Leptin protects mice from starvation-induced lymphoid atrophy and increases thymic cellularity in ob/ob mice. J Clin Invest 1999; 104: 1051-9.

12. Mattioli B, Straface E, Quaranta MG, Giordani L, Viora M. Leptin promotes differentiation and survival of human dendritic cells and licenses them for Th1 priming. J Immunol 2005; 174: 6820-8.

13. Martin-Romero C, Santos-Alvarez J, Goberna R, Sanchez-Margalet V. Human leptin enhances activation and proliferation of human circulating T lymphocytes. Cell Immunol 2000; 199: 15-24.

14. Tian G, Liang JN, Wang ZY, Zhou D. Emerging role of leptin in rheumatoid arthritis. Clin Exp Immunol 2014; 177: 557-70.

15. Oner SY, Volkan O, Oner C, Mengi A, Direskeneli H, Tasan DA. Serum leptin levels do not correlate with disease activity in rheumatoid arthritis. Acta Reumatol Port 2015; 40: 50-4.

16. Otero M, Lago R, Gomez R, et al. Changes in plasma levels of fat-derived hormones adiponectin, leptin, resistin and visfatin in patients with rheumatoid arthritis. Ann Rheum Dis 2006; 65: 1198-201.

17. Arnett FC, Edworthy SM, Bloch DA, et al. The American Rheumatism Association 1987 revised criteria for the classification of rheumatoid arthritis. Arthritis Rheum 1988; 31: 315-24.

18. Dervišević A, Babić N, Začiragić A, et al. Serum nitric oxide concentration in rheumatoid arthritis patients: the association with disease activity. Med J 2016; 22: 30-3.

19. Hensor EM, Emery P, Bingham SJ, Conaghan PG, Consortium Y. Discrepancies in categorizing rheumatoid arthritis patients by DAS-28(ESR) and DAS-28(CRP): can they be reduced? Rheumatology (Oxford) 2010; 49: 1521-9.

20. Andersson BL, Bjorntorp P, Seidell JC. Measuring obesity - classification and description of anthropometric data. Report on a WHO consultation on epidemiology of obesity. Copenhagen: Nutrition Unit, WHO Regional Office for Europe; EUR/ICP/NUT 1988; 125: 1-22.

21. Tsigosa C, Hainer V, Basdevant, A, et al. Management of obesity in adults: European Clinical Practice Guidelines. Eur J Obes 2008; 1: 106-16.

22. World Health Organization. Physical Status: The Use and Interpretation of Anthropometry. Report of a WHO Expert Committee. Technical Report Series No. 854. Geneva, Switzerland: World Health Organization 1995.

23. Ashwell M, Hsieh SD. Six reasons why the waist-toheight ratio is a rapid and effective global indicator for health risks of obesity and how its use could simplify the international public health message on obesity. Int J Food Sci Nutr 2005; 56: 303-7.

24. Meier U, Gressner AM. Endocrine regulation of energy metabolism: review of pathobiochemical and clinical chemical aspects of leptin, ghrelin, adiponectin, and resistin. Clin Chem 2004; 50: 1511-25.

25. Versini M, Jeandel PY, Rosenthal E, Shoenfeld Y. Obesity in autoimmune diseases: not a passive bystander. Autoimmun Rev 2014; 13: 981-1000.

26. Seven A, Guzel S, Aslan M, Hamuryudan V. Serum and synovial fluid leptin levels and markers of inflammation in rheumatoid arthritis. Rheumatol Int 2009; 29: 743-7.

27. Sarraf P, Frederich RC, Turner EM, et al. Multiple cytokines and acute inflammation raise mouse leptin levels: potential role in inflammatory anorexia. J Exp Med 1997; 185: 171-5. 
28. Rho YH, Solus J, Sokka T, et al. Adipocytokines are associated with radiographic joint damage in rheumatoid arthritis. Arthritis Rheum 2009; 60: 1906-14.

29. Otero M, Gomez Reino JJ, Gualillo O. Synergistic induction of nitric oxide synthase type II: in vitro effect of leptin and interferon-gamma in human chondrocytes and ATDC5 chondrogenic cells. Arthritis Rheum 2003; 48: 404-9.

30. Allam A, Radwan A. The relationship of serum leptin levels with disease activity in Egyptian patients with rheu matoid arthritis. Egypt Rheumatol 2012; 34: 185-90.

31. Popa C, Netea MG, Radstake TR, van Riel PL, Barrera P, van der Meer JW. Markers of inflammation are negatively correlated with serum leptin in rheumatoid arthritis. Ann Rheum Dis 2005; 64: 1195-8.

32. Hizmetli S, Kisa M, Gokalp N, Bakici MZ. Are plasma and synovial fluid leptin levels correlated with disease activity in rheumatoid arthritis? Rheumatol Int 2007; 27 335-8.

33. Targojska-Stdpniak B, Majdan M, Dryglewska M. Leptin serum levels in rheumatoid arthritis patients: relation to disease duration and activity. Rheumatol Int 2008; 28: 585-91.

34. Tokarczyk-Knapik A, Nowicki M, Wyrolak J. The relation between plasma leptin concentration and body fat mass in patients with rheumatoid arthritis. Pol Arch Med Wewn 2002; 108: 761-7.

35. Lee SW, Park MC, Park YB, Lee SK. Measurement of the serum leptin level could assist disease activity monitoring in rheumatoid arthritis. Rheumatol Int 2007; 27 . 537-40. 